\title{
miR-100 suppresses the proliferation and tumor growth of esophageal squamous cancer cells via targeting CXCR7
}

\author{
SHAO-MEI ZHOU ${ }^{1}$, FANG ZHANG $^{1}$, XUE-BIN CHEN $^{1}$, CAO-MING JUN $^{1}$, XIN JING $^{1}$, DENG-XIONG WEI ${ }^{1}$, \\ YANG XIA $^{1}$, YU-BAI ZHOU ${ }^{1}$, XIANG-QIAN XIAO $^{1}$, RUN-QING JIA $^{1}$, \\ JING-TAO LI ${ }^{1}$, WANG SHENG ${ }^{1}$ and YI ZENG ${ }^{1,2}$ \\ ${ }^{1}$ Department of Pharmacology and Biology, College of Life Science and Bioengineering, Beijing University of Technology, \\ Chaoyang, Beijing 100124; ${ }^{2}$ National Institute for Viral Disease Control and Prevention, \\ Chinese Center for Disease Control and Prevention, and State Key Laboratory for \\ Infectious Disease Prevention and Control, Beijing 100052, P.R. China
}

Received April 11, 2015; Accepted September 14, 2015

DOI: $10.3892 /$ or.2016.4701

\begin{abstract}
MicroRNAs are highly conserved non-coding RNAs that regulate gene expression at the post-transcriptional level, and play pivotal roles in cancer development and progression. miR-100 has been reported to be significantly downregulated in a variety of cancers, including esophageal cancer. However, the role of miR-100 in human esophageal cancer has not been fully elucidated. We demonstrated that overexpression of miR-100 in esophageal cancer cells markedly inhibited cell proliferation, migration and invasion as well as tumor growth. We subsequently showed that CXCR7 is a direct target gene of miR-100. Our results indicated that miR-100 plays a tumorsuppressor role in esophageal cancer and suggest its potential application for esophageal cancer treatment.
\end{abstract}

\section{Introduction}

Esophageal cancer is one of the most common cancers of the upper gastrointestinal tract worldwide with a variable geographic distribution. Esophageal squamous cell carcinoma (ESCC) and esophageal adenocarcinoma (EAC) have been identified as the two main histological types in regards to different etiologic and pathologic characteristics. EAC is common in Western countries while ESCC is frequently diagnosed in east Asia, particularly in China whose incidence in the high-risk northern and central China exceeds 100 cases/100,000 people/year (1). Despite remarkable

Correspondence to: Professor Wang Sheng or Professor Yi Zeng, Department of Pharmacology and Biology, College of Life Science and Bioengineering, Beijing University of Technology, 100 Pingleyuan, Chaoyang, Beijing 100124, P.R. China

E-mail: shengwang@bjut.edu.cn

E-mail: zengy@public.bta.net.cn

Key words: miR-100, esophageal squamous cell carcinoma, CXCR7, migration, proliferation, invasion improvements in the diagnosis and treatment of this cancer, the overall 5-year survival rate for advanced and metastatic esophageal cancer is less than $20 \%$ after surgery in China (1). Thus, an understanding of the molecular mechanisms of the pathogenesis of esophageal cancer is important for identifying more tumor-specific biomarkers and therapeutic targets for early diagnosis and treatment.

miRNAs are an endogenous class of highly-conserved 20-25 nucleotide single-stranded non-coding RNAs that regulate gene expression at the post-transcriptional level by binding to the 3'-untranslated region (3'-UTR) of mRNA which subsequently leads to mRNA degradation and translation repression. Emerging evidence demonstrates that a single gene may be targeted by different miRNAs, while a single miRNA can modulate multiple gene expression due to the imperfect complementarity with target mRNAs, which allows miRNAs to control a variety of physiological processes such as cell proliferation, differentiation, apoptosis and angiogenesis (2). Thus, aberrant expression of miRNAs are thought to play critical roles in cancer initiation and progression via targeting various oncogenes and tumor-suppressor genes $(3,4)$.

Aberrant miRNA expression patterns have been reported in esophageal cancer compared to corresponding non-malignant tissues $(5,6)$. Several miRNAs were found to be significantly downregulated in ESCC such as miR-100, miR-203, miR-205, miR-145, miR-27b, miR-375, miR-125b and let-7c $(7,8)$, suggesting that they may exert tumor-suppressive effects. We previously demonstrated that miR-203 promoted apoptosis and inhibited the proliferation and migration of esophageal cancer cells through downregulation of Ran expression (9). miR-100 is located on chromosome 11 at 11q24.1 (Gene ID: 406892) (10). A previous study showed that overexpression of miR-100 induced apoptosis of esophageal cancer cells by targeting mTOR (11). However, further studies are required to provide additional insights into the molecular mechanisms underlying the regulatory activities of miR-100 in esophageal cancer. In the present study, the regulatory effects of miR-100 on the proliferation, migration and tumor growth of esophageal cancer cells and its molecular mechanisms were characterized. 


\section{Materials and methods}

Plasmid construction. The hsa-miR-100 (miR-100) precursor was synthesized by Songon Tech (Beijing, China) and subcloned into the pcDNA6.2-GW/EmGFP-miR vector (referred to as pcDNA6.2/miR-100) according to the manufacturer's instructions (Invitrogen, Carlsbad, CA, USA). Scramble miRNA was cloned into the same vector and used as a negative control (named pcDNA6.2/miR-NC). The sequence of the control miRNA was: 5'-AGGTACGAAACGCTAAGAAT-3'. To construct the luciferase reporter vector, the human CXCR7 3'-UTR containing putative binding sites for miR-100 was amplified by PCR and cloned in pmirGLO Dual-Luciferase miRNA Target Expression Vector (Promega, Madison, WI, USA). The construct was named pmiR-GLO-CXCR7. The primers were as follows: forward primer, 5'-GGGAGCTCTC TGCCCTGGAGAGGCTCTG-3' and reverse primer, 5'-CGT CTAGACAAAACTGAAGTCACGCTA-3'. The accuracy of all cloning was confirmed by sequencing.

Cell transfection. Human esophageal squamous cancer cell line (Ec-109) (kindly provided by Dr Ling Zhou from the Institute for Viral Disease Control and Prevention, Chinese Center for Disease Control and Prevention) was maintained in RPMI-1640 medium supplemented with $10 \%$ fetal bovine serum (FBS), $100 \mathrm{U} / \mathrm{ml}$ penicillin and $100 \mu \mathrm{g} / \mathrm{ml}$ streptomycin in a humidified incubator with $5 \% \mathrm{CO}_{2}$ at $37^{\circ} \mathrm{C}$. All cell culture materials were obtained from Gibco, USA. Lipofectamine 2000 (Invitrogen) was used for cell transfection. Briefly, cells at $\sim 60 \%$ confluency in 6 -well plates were transfected with the plasmid pcDNA6.2/miR-100 or control vector pcDNA6.2/miR-NC. Blasticidin $(4 \mu \mathrm{g} / \mathrm{ml})$ was applied to select stable miR-100-overexpressing clones. The expression of miR-100 was confirmed by real-time PCR after 3 weeks of selection from individual clones.

Quantitative real-time PCR (RT-qPCR) analysis. The expression of mature miR-100 and the primary transcript of CXCR7 was analyzed by RT-qPCR. Total RNA was extracted from cultured cells by TRIzol reagent (Invitrogen) based on the provided protocols. Total RNA (1 $\mu \mathrm{g})$ was applied for reverse transcription to synthesize miRNA cDNA using NCode ${ }^{\mathrm{TM}}$ VILO $^{\mathrm{TM}}$ miRNA cDNA synthesis kit (Invitrogen). RT-qPCR analysis was performed using EXPRESS SYBR ${ }^{\circledR}-$ GreenER $^{\mathrm{TM}}$ miRNA RT-qPCR kit (Invitrogen) based on instructions. Reverse transcription mix $(20 \mu \mathrm{l})$ was amplified by PCR with denaturation at $95^{\circ} \mathrm{C}$ for $2 \mathrm{~min}$ and 40 cycles at $95^{\circ} \mathrm{C}$ for $10 \mathrm{sec}$ and $60^{\circ} \mathrm{C}$ for $1 \mathrm{~min}$. U6 was applied as an endogenous control for normalization. Each sample was analyzed in triplicate. The forward primers that target miR-100 or U6 were purchased from Songon Tech.

To analyze the expression of CXCR7, $1 \mu \mathrm{g}$ of total RNA was reverse transcribed in a final volume of $20 \mu \mathrm{l}$ to synthesize first-strand cDNA using ImProm-II ${ }^{\mathrm{TM}}$ reverse transcription system (Promega) based on the instructions of the manufacturer. The transcript levels were detected using Brilliant ${ }^{\circledR}$ II SYBR $^{\circledR}$-Green qPCR Master Mix (Stratagene, USA) to monitor amplification. $\beta$-actin served as an endogenous control for normalization. PCR reactions $(25 \mu \mathrm{l})$ in triplicate were carried out by an initial denaturation at $95^{\circ} \mathrm{C}$ for $10 \mathrm{~min}$ followed by
40 cycles, each consisting of $30 \mathrm{sec}$ at $95^{\circ} \mathrm{C}, 30 \mathrm{sec}$ at $58^{\circ} \mathrm{C}$, $30 \mathrm{sec}$ at $72^{\circ} \mathrm{C}$, and then 1 cycle for melting curve consisting of $1 \mathrm{~min}$ at $95^{\circ} \mathrm{C}, 30 \mathrm{sec}$ at $55^{\circ} \mathrm{C}, 30 \mathrm{sec}$ at $95^{\circ} \mathrm{C}$. Primer sequences used were as follows: 5'-GGCTATGACACGCACTGCTACA-3' (forward primer for CXCR7) and 5'-TGGTTGTGCTGCACG AGACT-3' (reverse primer for CXCR7); 5'-AGAAAATCTGG CACCACACC-3' (forward primer for $\beta$-actin) and 5'-TAGC ACAGCCTGGATAGCAA-3' (reverse primer for $\beta$-actin). The $2^{-\Delta \Delta \mathrm{Ct}}$ method for relative quantification of gene expression was used to determine miRNA and CXCR7 mRNA expression levels. RT-qPCR primers were designed using Primer Express software (version 5.0; Applied Biosystems).

Cell proliferation assay. Cells (2,000 cells/well) were passaged in 96-well plates in RPMI-1640 culture medium containing $10 \mu \mathrm{g} / \mu 1$ blasticidin, supplemented with 10 or $7 \%$ FBS. Cell proliferation were measured by the OD values using Cell Counting Kit-8 (CCK-8) (Dojindo, Japan). The absorbance was measured at $450 \mathrm{~nm}$ on a microplate reader (PerkinElmer, USA), and the reference light was $650 \mathrm{~nm}$. Every sample was measured for three times.

Cell invasion and migration assays. Transwell insert chambers (Corning, Corning, NY, USA) with $8-\mu$ m pores were used to conduct these assays. For the migration assay, $1 \times 10^{5}$ cells were seeded into the upper chamber in serum-free medium in triplicate. Medium containing 20\% FBS in the lower chamber served as the chemoattractant. After incubation for $24 \mathrm{~h}$ at $37^{\circ} \mathrm{C}$ in a $5 \% \mathrm{CO}_{2}$ humidified incubator, cells in the upper chambers were removed by wiping with a cotton swab and cells that had migrated to the lower surface of the filter were fixed with $4 \%$ formaldehyde overnight at $4{ }^{\circ} \mathrm{C}$ and stained with $0.2 \%$ crystal violet for $10 \mathrm{~min}$. Cell migration was scored by counting five random fields/filter under a light microscope. For the invasion assay, $3 \times 10^{5}$ cells were plated into upper chambers precoated with Matrigel (BD, USA) in serum-free medium in triplicate. Medium with 20\% FBS was added to the lower chamber to serve as the chemoattractant. After incubation for $24 \mathrm{~h}$ at $37^{\circ} \mathrm{C}$, non-invading cells on the upper surface of the filter were removed by wiping with a cotton swab and invading cells that had migrated to the lower surface of the filter were fixed, stained and scored as described above.

Soft agar assay for colony formation. Cells $(2,000)$ were seeded in $1.5 \mathrm{ml}$ of standard growth medium containing $0.33 \%$ low-melting-temperature soft agar (SeaKem; FMC Corporation) and plated onto a $3 \mathrm{ml}$ layer of solidified $0.66 \%$ soft agar in the same medium in a 35-mm tissue culture dish. Cultures were fed once a week with $0.5 \mathrm{ml}$ of complete medium. Each cell clone tested was seeded in triplicate. The cell colonies becoming visible microscopically after $3 \pm 4$ weeks were scored weekly, and photographed with a Olympus microscope (Japan).

In vivo tumor formation assay. Female athymic BALB/c nude mice 4-6 weeks old were purchased from the Laboratory Animal Center of the Army Research Center (Beijing, China), and carefully fostered under the guidelines for the care and use of laboratory animals of the local government. All mice were housed under a pathogen-free condition. All 
A

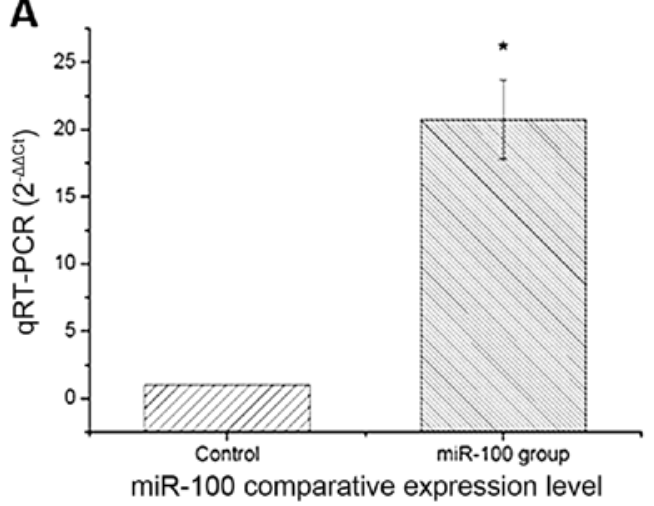

C

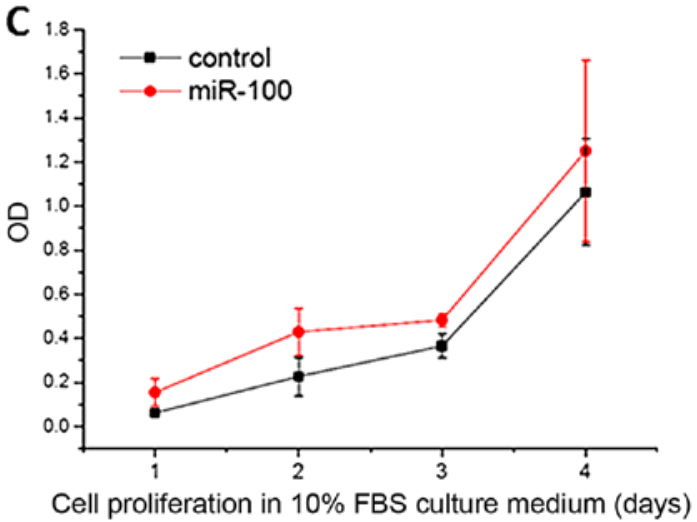

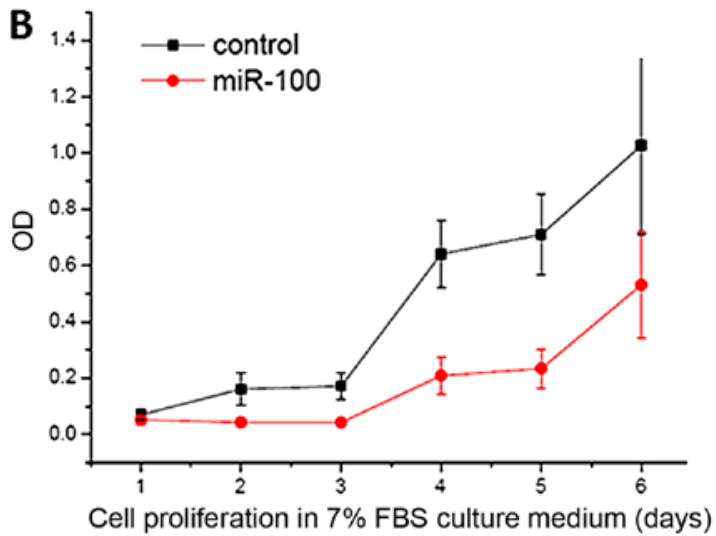

Figure 1. miR-100 expression and cell proliferation. (A) Ectopic expression of miR-100 was quantitatively detected by RT-PCR. Data are presented as means \pm SD (n=3), ${ }^{*} \mathrm{p}<0.05$. (B) Cell proliferation in culture medium with $7 \%$ of FBS. (C) Cell proliferation in culture medium with $10 \%$ of FBS. Data are shown as the average of triplicate measurements with standard error bars.

experiments were performed with guidelines provided by the National Cancer Insitute (NIH; USA). For xenografts, 10 mice were randomly separated into 2 groups. Cells $\left(2 \times 10^{6}\right)$ that stably expressed miR-100 or miR-NC were suspended in serum-free RPMI-1640 medium and injected subcutaneously into the flank, respectively. Five weeks post-injection, the mice were sacrificed and photographed. Tumor volumes $\left(\mathrm{cm}^{3}\right)$ were calculated using the following standard formula: [length $\mathrm{x}$ width] $\mathrm{x}$ [(length + width $) / 2]$.

Luciferase target gene reportor assay. Two groups of Ec-109 cells (stably overexpressing miR-100 or miR-NC) were seeded in 6-well plates for $\sim 24 \mathrm{~h}$ to reach $60 \%$ confluency, and then transiently transfected with the pmiR-GLO-CXCR7 gene report vector for $12 \mathrm{~h}$. Empty vector (pmiR-GLO-NC) was used as a control. Luciferase activity was analyzed using the Dual-Glo ${ }^{\circledR}$ Luciferase Assay system (Promega), which was analyzed by three independent experiments performed in triplicate.

Western blotting. Proteins were extracted from the miR-100expressing or the control cells using the Membrane and Cytosol Protein Extraction kit (Beyotime, China). Protein concentrations were determined by the BCA protein assay kit (Tiangen, China). Protein samples were denatured by boiling for 5 min and were loaded onto SDS-PAGE (10\% polyacrylamide gel) for electrophoresis, and then transferred onto methanolactivated polyvinylidene fluoride (PVDF) membranes
(Bio-Rad Laboratories, USA). Non-specific reactivity on the membranes was blocked by $5 \%$ skim milk [non-fat dry milk in Tris-buffered saline with Tween-20 (TBST)] overnight at $4^{\circ} \mathrm{C}$, and then washed with TBST. Primary antibodies for human $\beta$-actin (Cell Signaling Technology, Danvers, MA, USA) or CXCR7 (Bioss, China) were incubated with the membranes overnight at $4^{\circ} \mathrm{C}$, respectively. The membranes were then incubated with the secondary antibody, conjugated with fluorescent dyes: IRDye 800CW (KPL, Gaithersburg, MD, USA) for $1 \mathrm{~h}$. After washing, the membranes were developed under the Odyssey Infrared Imaging system (LI-COR Biosciences, Lincoln, NE, USA) to obtain the blotting images.

Statistical analysis. Data are presented as mean \pm SD of at least three independent experiments. The differences between group were analyzed using the Student's t-test. A p-value of $<0.05$ was considered statistically significant for all tests. Analyses were performed using statistical analysis software SPSS 19.

\section{Results}

miR-100 inhibits cell proliferation, migration and invasion of esophageal cancer cells. In the present study, the miR-100 precursor and scramble miRNAs were exogenously expressed in esophageal cancer cells and stable miRNA-expressing cells were acquired by blasticidin. The ectopic expression of mature miR-100 in the transfectants was initially confirmed 
A

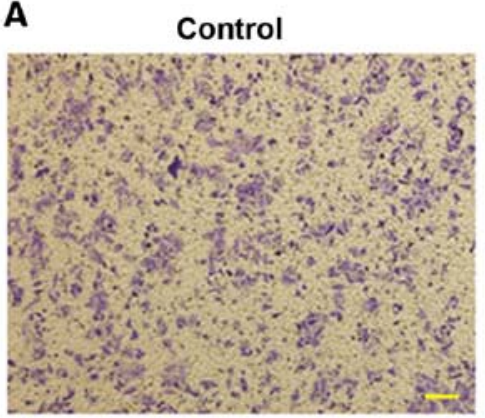

C

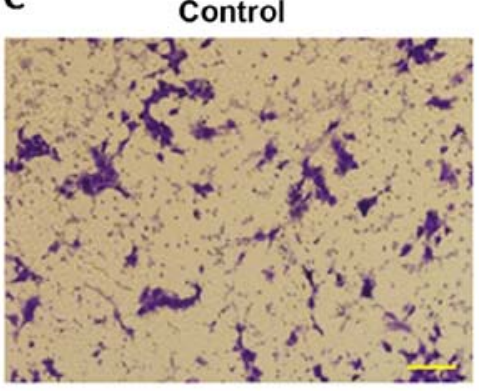

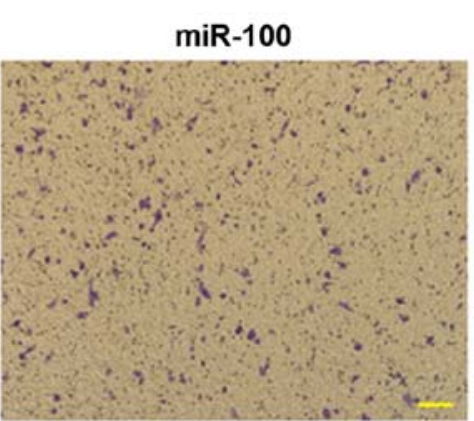
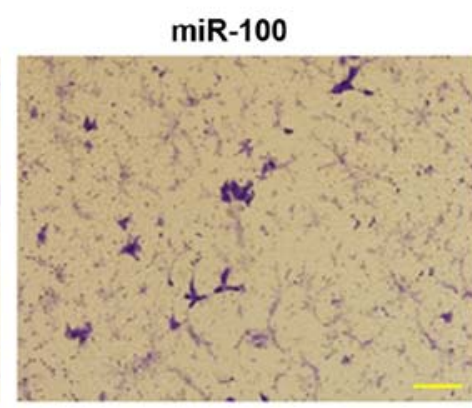

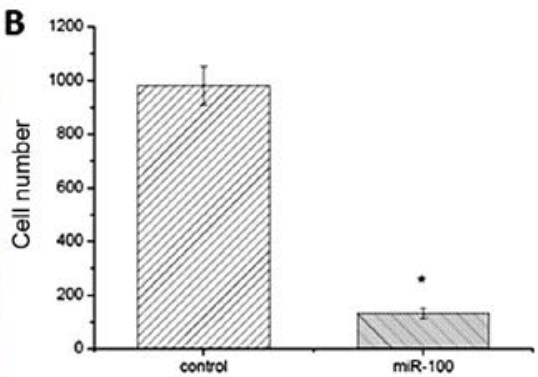

Cell migration assay

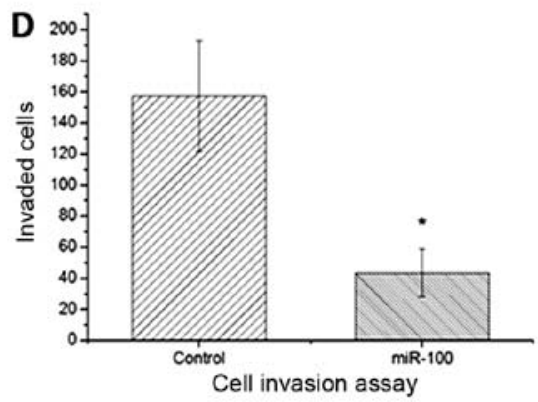

Figure 2. Overexpression of miR-100 suppresses the migration and invasion of esophageal cancer cells. (A) Images of Transwell filters showing the cells that crossed an 8- $\mu \mathrm{m}$ pore size membrane through migration without Matrigel. Scale bar, $50 \mu \mathrm{m}$. (B) Quantitative measurement of cell migration was performed in triplicate and is presented as means $\pm \mathrm{SD},{ }^{*} \mathrm{p}<0.05$. (C) Images of Transwell filters showing the cells which crossed an $8-\mu \mathrm{m}$ pore size membrane with Matrigel. Scale bar, $100 \mu \mathrm{m}$. (D) Quantitative evaluation of cell migration was performed in triplicate and data are presented as means \pm SD, ${ }^{*}<<0.05$.
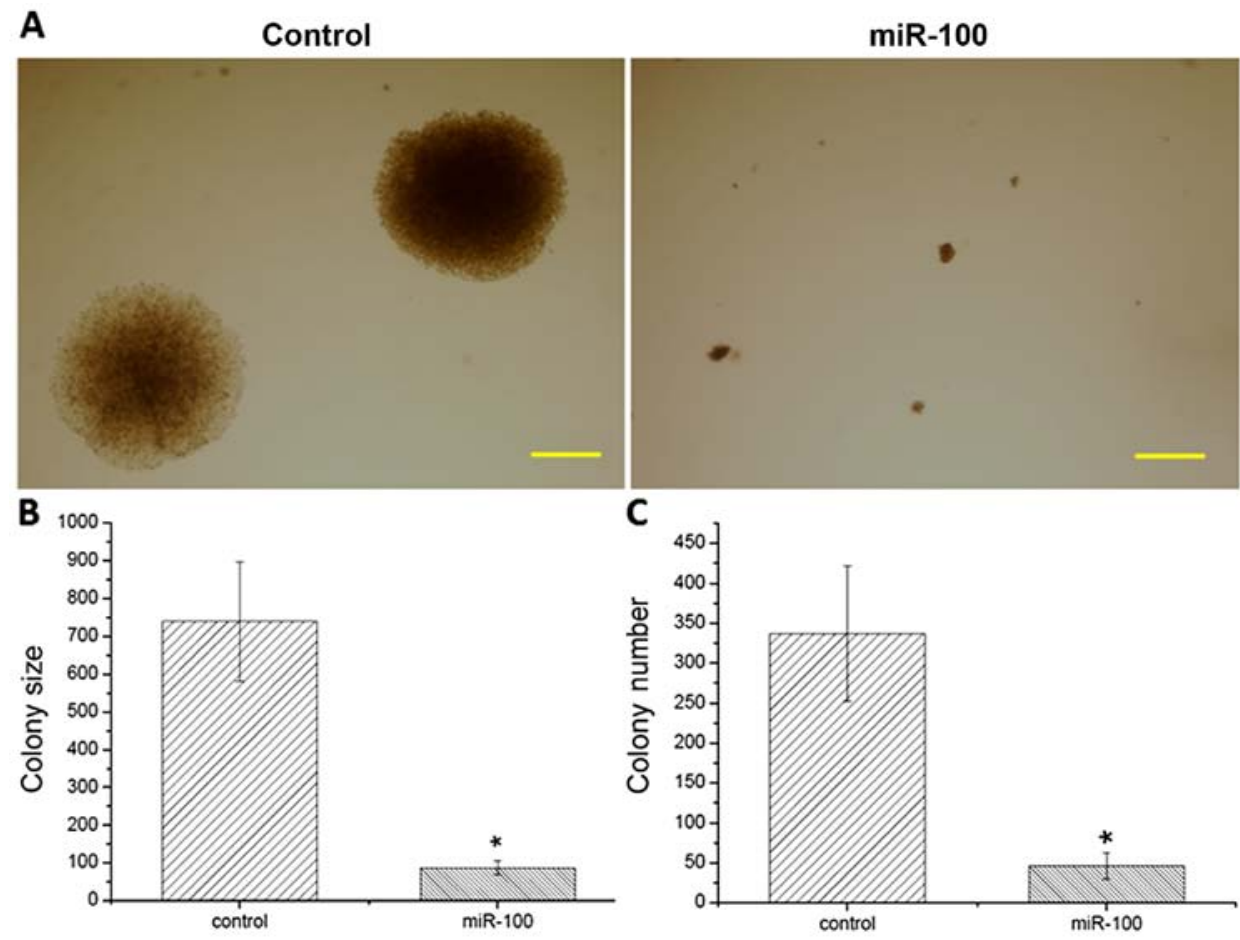

Figure 3. Soft agar assay. (A) Colony formation assay was conducted to test anchorage-independent growth in soft agar of scramble miRNA- and miR-100-transfected Ec-109 cells. Scale bar, $200 \mu \mathrm{m}$. (B) Quantitative analysis of colony formation was performed in triplicate and is presented as means \pm SD, "p $<0.05$. (C) Quantitative analysis of colony number was performed in triplicate and data are presented as means $\pm \mathrm{SD},{ }^{*} \mathrm{p}<0.05$.

by qRT-PCR (Fig. 1A). To investigate the potential regulatory effects of miR-100 on esophageal cancer cells, CCK-8 and Transwell assays were used to evaluate the proliferation, migration and invasion of the esophageal cancer cells upon
miR-100 transfection, respectively. The data showed that miR-100 overexpression significantly inhibited cell growth when cells were cultured in 7\% of FBS compared to the scramble miRNA (control) (Fig. 1B). However, no obvious 


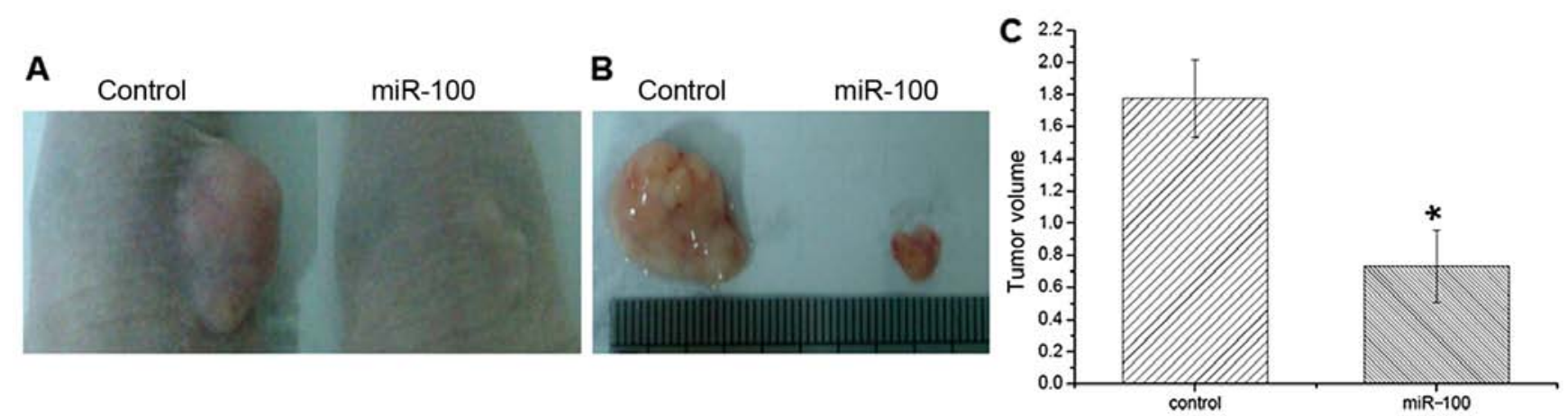

Figure 4. In vivo tumor growth. (A) Tumor formation in nude mice. (B) Representative tumor tissues were extracted from mice inoculated with scramble miRNA- and miR-100-transfected Ec-109 cells. (C) Tumor volume was calculated and data are shown as means \pm SD, ${ }^{*} \mathrm{p}<0.05$.
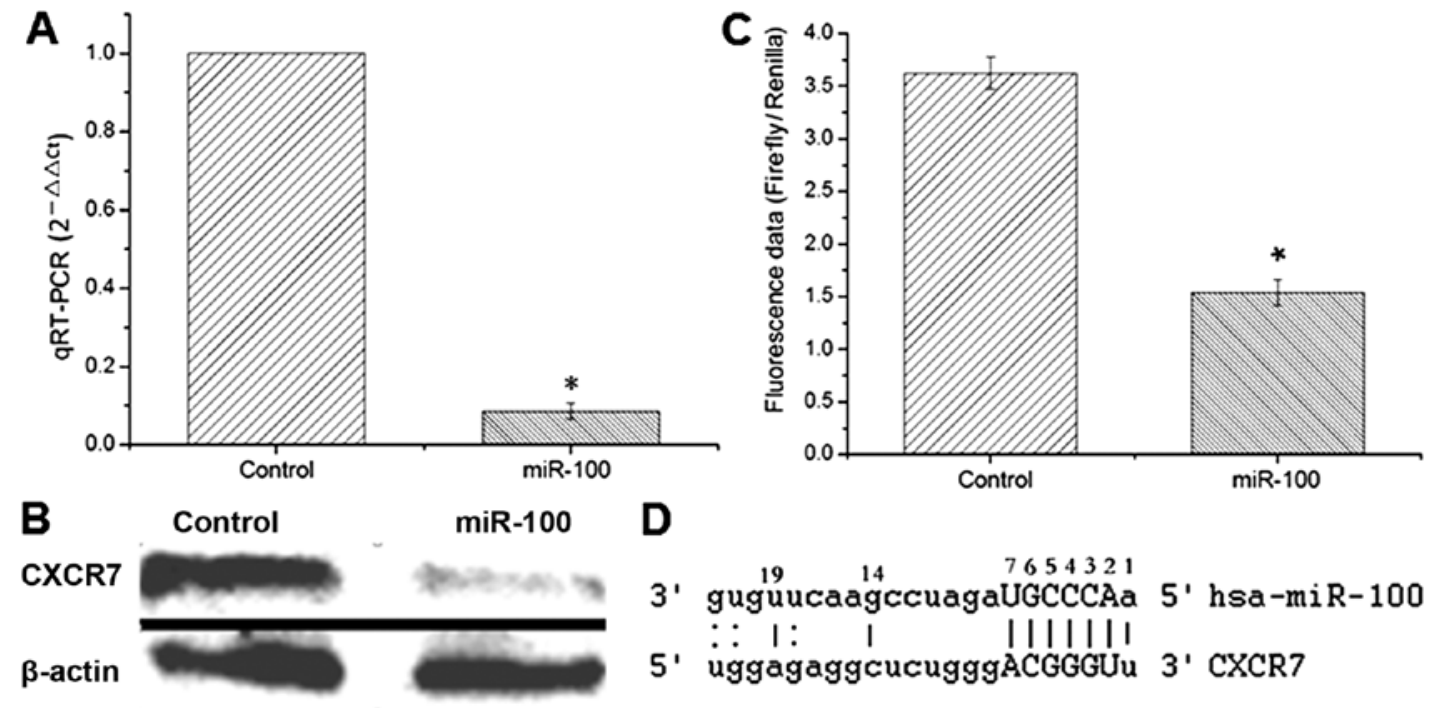

Figure 5. CXCR7 expression and luciferase assay. (A) CXCR7 expression was quantitatively determined by RT-PCR. (B) CXCR7 expression was quantitatively analyzed by western blotting. (C) The reporter plasmid containing wild-type 3'-UTR of the CXCR7 gene was co-transfected into Ec-109 cells with the miR-100-expressing plasmid to evaluate luciferase activity. Empty plasmid without 3'-UTR of the CXCR7 gene was used as a control. Data are presented as means $\pm \mathrm{SD}(\mathrm{n}=3),{ }^{*} \mathrm{p}<0.05$. (D) Putative miR-100-binding sequence within the $3^{\prime}$-UTR of CXCR7 mRNA.

inhibition in cell growth was observed when cultured in $10 \%$ of FBS (Fig. 1C). Moreover, compared with the control, ectopic expression of miR-100 was able to suppress the migration (Fig. 2A and B) and invasion (Fig. 2C and D) of the esophageal cancer cells, implying a tumor-suppressor role of miR-100 in esophageal cancer.

miR-100 suppresses colony formation and the tumor growth of esophageal cancer cells. An anchorage-independent growth assay and xenograft transplantation experiment were further conducted to examine the effects of miR-100 on tumorigenesis in esophageal cancer cells. The results showed that large cell colonies were generated in the scramble miRNA-transfected cells (Fig. 3A). In contrast, overexpression of miR-100 inhibited colony formation and significantly reduced colony numbers in vitro when compared to the control (Fig. $3 \mathrm{~B}$ and $\mathrm{C}$ ). In vivo xenograft transplantation analysis further showed that miR-100 overexpression markedly suppressed tumor growth in nude mice (Fig. 4A and B). The tumor volume was much smaller than that of the controls (Fig. 4C), which was consistent with the in vitro colony formation assay. The obtained data suggest that miR-100 plays a suppressive role in the tumorigenesis of esophageal cancer.

CXCR7 is a target gene of miR-100. Several computational prediction websites such as TargetScan, PicTar and MiRanda and the target prediction methods as previously reported $(12,13)$ were used to identify functionally relevant targets of miR-100. The expression of CXCR7 which contains a putative target sequence of miR-100 in 3'-UTR was quantitatively examined by both RT-PCR and western blotting. The data showed that the expression of CXCR7 was significantly decreased in the miR-100-expressing cells compared to that noted in the control cells (Fig. 5A and B). Luciferase assay was thereafter used to investigate whether CXCR7 is a direct target of miR-100. The 3'-UTR region of the CXCR7-encoding gene containing the putative binding site of miR-100 was subcloned into the luciferase reporter vector and co-transfected with miR-100 into esophageal cancer cells. Cells co-transfected with the empty vector and miR-100 were used as a control. The results 
showed that luciferase activity was markedly reduced in the reporter construct containing 3'-UTR of CXCR7 compared to that in the empty vector control (Fig. 5C), indicating that CXCR7 is a direct downstream target gene of miR-100 and miR-100 downregulates the expression of CXCR7 through direct binding to its 3'-UTR (Fig. 5D).

\section{Discussion}

Downregulation of miR-100 has been reported in a variety of different types of cancers including ESCC (14-18). In the present study, miR-100 was overexpressed in ESCC cells to elucidate the biological functions of miR-100 in ESCC. The obtained data showed that exogenous expression of miR-100 in ESCC cells was able to significantly suppress cell proliferation, migration and invasion and inhibit tumor growth in vivo, suggesting a tumor-suppressive role of miR-100 in esophageal cancer cells. A number of tumor-associated genes such as FGFR3, HOXA1, mTOR, IGF1-R, AGO2 and Rac1 have been reported to be modulated by miR-100 in different types of tumors and are involved in the miR-100-mediated inhibitory effects on cell proliferation, migration and invasion $(11,19$ 23). In the present study, we showed that CXCR7 is a direct target gene of miR-100 as validated by luciferase assay and it is significantly downregulated in miR-100-overexpressing cells.

CXCR7 was initially named receptor dog cDNA 1 (RDC1), which was cloned from a canine thyroid cDNA library and identified as an atypical chemokine receptor (24). The human RDC1 gene is located at chromosome region 2q37.3. Subsequent to showing that RDC1 acts as a receptor of both chemokines of CXCL12 and CXCL11, RDC1 was officially renamed CXCR7 as a seventh receptor of the CXC class of the chemokine receptor family $(25,26)$. Chemokine receptors are seven-transmembrane receptors coupled to $\mathrm{G}$-proteins and are responsible to initiate a cascade of signal transduction events (27). Increasing evidence suggests that chemokines and their receptors play pivotal roles in tumor growth, angiogenesis and distant metastases to lymph nodes and bone marrow. Chemokine CXCL12 is a broadly expressed cytokine (28-30). CXCR7 is highly expressed in the majority of tumor cells and activation of the CXCR7 signaling pathway by CXCL12 has been found to be coupled with the enhanced proliferation and increased metastasis and invasive activities of tumor cells $(29,30)$. Accordingly, it has been shown that CXCR7 knockdown by gene silencing significantly inhibited the proliferation, migration and invasion of hepatocellular carcinoma cells and suppressed tumor growth, angiogenesis and lung metastasis in a xenograft model of hepatocellular carcinoma $(31,32)$. However, CXCR7 is overexpressed in esophageal cancer, particularly in ESCC (33), suggesting the critical regulatory effects of CXCR7 on ESCC progression.

In conclusion, CXCR7, as a chemokine receptor, is tightly implicated in the initiation, adhesion, angiogenesis and metastasis of various cancers. Previous evidence suggests that CXCR7 is a potential therapeutic target against cancer $(34,35)$. In the present study, we showed that CXCR7 is a direct downstream target of miR-100, and overexpression of miR-100 efficiently suppresses CXCR7 expression, indicating a great potential for miR-100 as an anticancer therapeutic candidate.

\section{Acknowledgements}

The present study was supported by grants from the NSFC (31440059), the Project of Construction of Innovative Teams and Teacher Career Development for Universities and Colleges Under Beijing Municipality (IDHT20140504), the Beijing Natural Science Foundation (5153024), and the Beijing City Board of Education Science and Technology Program (KM201510005027).

\section{References}

1. Demeester SR: Epidemiology and biology of esophageal cancer. Gastrointest Cancer Res 3 (Suppl): S2-S5, 2009.

2. Bartel DP: MicroRNAs: Genomics, biogenesis, mechanism, and function. Cell 116: 281-297, 2004.

3. Esquela-Kerscher A and Slack FJ: Oncomirs - microRNAs with a role in cancer. Nat Rev Cancer 6: 259-269, 2006.

4. Medina PP and Slack FJ: microRNAs and cancer: An overview. Cell Cycle 7: 2485-2492, 2008.

5. Guo Y, Chen Z, Zhang L, Zhou F, Shi S, Feng X, Li B, Meng X, Ma X, Luo M, et al: Distinctive microRNA profiles relating to patient survival in esophageal squamous cell carcinoma. Cancer Res 68: 26-33, 2008.

6. Feber A, Xi L, Luketich JD, Pennathur A, Landreneau RJ, Wu M, Swanson SJ, Godfrey TE and Litle VR: MicroRNA expression profiles of esophageal cancer. J Thorac Cardiovasc Surg 135: 255-260, 2008

7. Hu Y, Correa AM, Hoque A, Guan B, Ye F, Huang J, Swisher SG, Wu TT, Ajani JA and Xu XC: Prognostic significance of differentially expressed miRNAs in esophageal cancer. Int J Cancer 128: 132-143, 2011.

8. Li X, Wainscott C and Xi Y: MicroRNA provides insight into understanding esophageal cancer. Thorac Cancer 2: 134-142, 2011.

9. Zhang F, Yang Z, Cao M, Xu Y, Li J, Chen X, Gao Z, Xin J, Zhou S, Zhou Z, et al: MiR-203 suppresses tumor growth and invasion and down-regulates miR-21 expression through repressing Ran in esophageal cancer. Cancer Lett 342: 121-129, 2014.

10. Qin C, Huang RY and Wang ZX: Potential role of miR-100 in cancer diagnosis, prognosis, and therapy. Tumour Biol 36: 1403-1409, 2015.

11. Sun J, Chen Z, Tan X, Zhou F, Tan F, Gao Y, Sun N, Xu X, Shao K and He J: MicroRNA-99a/100 promotes apoptosis by targeting mTOR in human esophageal squamous cell carcinoma. Med Oncol 30: 411, 2013.

12. Laganà $A$, Forte $S$, Russo F, Giugno R, Pulvirenti $A$ and Ferro A: Prediction of human targets for viral-encoded microRNAs by thermodynamics and empirical constraints. J RNAi Gene Silencing 6: 379-385, 2010.

13. Veksler-Lublinsky I, Shemer-Avni Y, Kedem K and ZivUkelson M: Gene bi-targeting by viral and human miRNAs. BMC Bioinformatics 11: 249, 2010.

14. Shi W, Alajez NM, Bastianutto C, Hui AB, Mocanu JD, Ito E, Busson P, Lo KW, Ng R, Waldron J, et al: Significance of Plk1 regulation by miR-100 in human nasopharyngeal cancer. Int $\mathrm{J}$ Cancer 126: 2036-2048, 2010.

15. Fu HL, Wu P, Wang XF, Wang JG, Jiao F, Song LL, Xie H, Wen XY, Shan HS, Du YX, et al: Altered miRNA expression is associated with differentiation, invasion, and metastasis of esophageal squamous cell carcinoma (ESCC) in patients from Huaian, China. Cell Biochem Biophys 67: 657-668, 2013.

16. Zhang C, Wang C, Chen X, Yang C, Li K, Wang J, Dai J, Hu Z, Zhou X, Chen L, et al: Expression profile of microRNAs in serum: A fingerprint for esophageal squamous cell carcinoma. Clin Chem 56: 1871-1879, 2010.

17. Zhang N, Fu H, Song L, Ding Y, Wang X, Zhao C, Zhao Y, Jiao $\mathrm{F}$ and Zhao $\mathrm{Y}$ : MicroRNA-100 promotes migration and invasion through mammalian target of rapamycin in esophageal squamous cell carcinoma. Oncol Rep 32: 1409-1418, 2014.

18. Gebeshuber CA and Martinez J: miR-100 suppresses IGF2 and inhibits breast tumorigenesis by interfering with proliferation and survival signaling. Oncogene 32: 3306-3310, 2013. 
19. Bi Y, Jing Y and Cao Y: Overexpression of miR-100 inhibits growth of osteosarcoma through FGFR3. Tumour Biol 36: 8405-8411, 2015.

20. Xiao F, Bai Y, Chen Z, Li Y, Luo L, Huang J, Yang J, Liao H and Guo L: Downregulation of HOXA1 gene affects small cell lung cancer cell survival and chemoresistance under the regulation of miR-100. Eur J Cancer 50: 1541-1554, 2014.

21. Zhou HC, Fang JH, Luo X, Zhang L, Yang J, Zhang C and Zhuang SM: Downregulation of microRNA-100 enhances the ICMT-Rac1 signaling and promotes metastasis of hepatocellular carcinoma cells. Oncotarget 5: 12177-12188, 2014

22. Wang M, Ren D, Guo W, Wang Z, Huang S, Du H, Song L and Peng X: Loss of miR-100 enhances migration, invasion, epithelial-mesenchymal transition and stemness properties in prostate cancer cells through targeting Argonaute 2. Int J Oncol 45: 362-372, 2014.

23. Huang JS, Egger ME, Grizzle WE and McNally LR: MicroRNA100 regulates IGF1-receptor expression in metastatic pancreatic cancer cells. Biotech Histochem 88: 397-402, 2013.

24. Libert F, Parmentier M, Lefort A, Dumont JE and Vassart G: Complete nucleotide sequence of a putative $\mathrm{G}$ protein coupled receptor: RDC1. Nucleic Acids Res 18: 1917, 1990.

25. Tarnowski M, Liu R, Wysoczynski M, Ratajczak J, Kucia M and Ratajczak MZ: CXCR7: A new SDF-1-binding receptor in contrast to normal $\mathrm{CD} 34^{+}$progenitors is functional and is expressed at higher level in human malignant hematopoietic cells. Eur J Haematol 85: 472-483, 2010.

26. Naumann U, Cameroni E, Pruenster M, Mahabaleshwar H, Raz E, Zerwes HG, Rot A and Thelen M: CXCR7 functions as a scavenger for CXCL12 and CXCL11. PLoS One 5: e9175, 2010.

27. Eva $\mathrm{C}$ and Sprengel R: A novel putative G protein-coupled receptor highly expressed in lung and testis. DNA Cell Biol 12: 393-399, 1993.

28. Miao Z, Luker KE, Summers BC, Berahovich R, Bhojani MS Rehemtulla A, Kleer CG, Essner JJ, Nasevicius A, Luker GD, et al: CXCR7 (RDC1) promotes breast and lung tumor growth in vivo and is expressed on tumor-associated vasculature. Proc Natl Acad Sci USA 104: 15735-15740, 2007.
29. Sun X, Cheng G, Hao M, Zheng J, Zhou X, Zhang J, Taichman RS, Pienta KJ and Wang J: CXCL12 / CXCR4 / CXCR7 chemokine axis and cancer progression. Cancer Metastasis Rev 29: 709-722, 2010.

30. Keeley EC, Mehrad B and Strieter RM: CXC chemokines in cancer angiogenesis and metastases. Adv Cancer Res 106: 91-111, 2010.

31. Xue TC, Chen RX, Han D, Chen J, Xue Q, Gao DM, Sun RX, Tang ZY and Ye SL: Down-regulation of CXCR7 inhibits the growth and lung metastasis of human hepatocellular carcinoma cells with highly metastatic potential. Exp Ther Med 3: 117-123, 2012.

32. Zheng K, Li HY, Su XL, Wang XY, Tian T, Li F and Ren GS: Chemokine receptor CXCR7 regulates the invasion, angiogenesis and tumor growth of human hepatocellular carcinoma cells. J Exp Clin Cancer Res 29: 31, 2010.

33. Tachezy M, Zander H, Gebauer F, von Loga K, Pantel K, Izbicki JR and Bockhorn M: CXCR7 expression in esophageal cancer. J Transl Med 11: 238, 2013.

34. Heckmann D, Maier P, Laufs S, Li L, Sleeman JP, Trunk MJ, Leupold JH, Wenz F, Zeller WJ, Fruehauf S, et al: The disparate twins: A comparative study of CXCR4 and CXCR7 in SDF-1 $\alpha$ induced gene expression, invasion and chemosensitivity of colon cancer. Clin Cancer Res 20: 604-616, 2014.

35. Guillemot E, Karimdjee-Soilihi B, Pradelli E, Benchetrit M, Goguet-Surmenian E, Millet MA, Larbret F, Michiels JF, Birnbaum D, Alemanno P, et al: CXCR7 receptors facilitate the progression of colon carcinoma within lung not within liver. Br J Cancer 107: 1944-1949, 2012. 